\title{
Delivery of anthropogenic bioavailable iron from mineral dust and combustion aerosols to the ocean
}

\author{
A. Ito and Z. Shi \\ Correspondence to: A. Ito (akinorii@jamstec.go.jp)
}

The copyright of individual parts of the supplement might differ from the CC-BY 3.0 licence. 
This supplementary document contains detailed descriptions of the methodologies for iron $(\mathrm{Fe})$ dissolution scheme.

\section{Recent global modeling studies of oxalate-promoted Fe dissolution from dust aerosols}

Increased attention has been given to the organic acids for promoting $\mathrm{Fe}$ dissolution from mineral dust aerosols in global models (Luo and Gao, 2010; Johnson and Meskhidze, 2013; Myriokefalitakis et al., 2015). Luo and Gao (2010) prescribed $\mathrm{pH}$ and oxalate/hematite ratio dependent dissolution rates of hematite for mineral dust based on laboratory experiments by $\mathrm{Xu}$ and Gao (2008). They also prescribed the molar ratio of oxalate to sulfate (2\%) to estimate the oxalate concentration in mineral dust, based on observations ranging from $0.46 \%$ to $5 \%$ (Yu et al. 2005). Note that the observed oxalate refers to the sum of oxalic acid and oxalate in aerosol particles, since ion chromatography allows quantification of oxalate independent of its chemical form (here referred to oxalate unless specified). Furthermore, laboratory measurements suggested that different oxalate species in solution (i.e., $\mathrm{HC}_{2} \mathrm{O}_{4}{ }^{-}$and $\mathrm{C}_{2} \mathrm{O}_{4}{ }^{2-}$ ) formed similar surface complexes (Yoon et al., 2004), increasing the activities of oxalate (hydrogen oxalate + oxalate) in solution at high oxalate concentration did not cause any significant increase in the surface concentration of oxalate, and hence on dissolution rate (Cama and Ganor, 2006). Johnson and Meskhidze (2013) used a linear relationship between oxalate-promoted dissolution rate and oxalate concentration in solution, based on the initial Fe release rates of $\mathrm{Fe}$ oxides and aluminosilicates at $\mathrm{pH}=4.7$ in one hour under cloud water conditions (Paris et al., 2011). Myriokefalitakis et al. (2015) applied the same equation to model-calculated oxalate concentration $\left(\left[\mathrm{C}_{2} \mathrm{O}_{4}{ }^{2-}\right]\right.$ ) in cloud water only (Johnson and Meskhidze, 2013; Paris et al., 2011).

\section{Materials and methodology in laboratory experiments}

The dust sample collected from a dry riverbed draining the Tibesti Mountains (South Libya; $\mathrm{N} 25^{\circ} 35^{\prime} \mathrm{E} 16^{\circ} 31^{\prime}$; hereafter termed Tibesti) was first dry-sieved to $<63 \mu \mathrm{m}$ and then wet-sieved to $<20 \mu \mathrm{m}$ (Tibesti-PM ${ }_{20}$ ) with $\sim 50 \mathrm{~mL}$ of Milli-Q water $(18.2 \mathrm{M} \Omega$ ). The sample suspensions were freeze dried and later were gently disaggregated before further experimentation. This procedure has been shown to have little impact on the Fe speciation and dissolution behavior at acidic pH (Shi et al., 2011). All experiments were performed at room temperature ( 298 K) under constant stirring $(\sim 50 \mathrm{rpm})$ and in dark conditions (wrapped in aluminium foil). Highly reactive Fe on the mineral surface was $0.63 \%$ of the total Fe (Shi et al., 2011). More crystalline Fe oxides on the mineral surface represent $37.7 \%$ of total Fe in the Tibesti dust. The rest of Fe is associated with aluminosilicates.

Aliquots of the dust suspension were separated by filtering through a $0.2 \mu \mathrm{m}$ filter directly into $\mathrm{HCl}$ (final concentration $0.2 \mathrm{~N} \mathrm{HCl}$ ), and the filtrates were stored for a maximum of one month at $4{ }^{\circ} \mathrm{C}$ until $\mathrm{Fe}$ analysis. The chosen time points to take samples were pre-set similar to Shi et al. (2011). Filtration through $0.2 \mu \mathrm{m}$ pore sized filters is commonly used for measurements of dissolved species from dust suspension, especially at near-neutral $\mathrm{pH}$. Fe colloids tend to aggregate or adhere to mineral surface, which are efficiently retained by a $0.2 \mu \mathrm{m}$ filter (Shi et al., 2009, 2015). Spectrophotometric ferrozine method was used to quantify the dissolved $\mathrm{Fe}$ concentration in this study. The solutions from the high ionic experiments $\left(I>3 \mathrm{~mol} \mathrm{~L}^{-1}\right)$ were diluted 100 times with acidified Milli-Q water $\left(0.01 \mathrm{~mol} \mathrm{~L}^{-1} \mathrm{HCl}\right)$ before measurement to avoid interferences. The precision of Fe measurement is $\pm 1.2 \%(1 \mathrm{~s}, \mathrm{n}=6)$. The detection limit for 
dissolved Fe is $0.05 \mu \mathrm{M}$ (Shi et al., 2015), which is much lower than the measurements in our experiments.

\section{Effects of inorganic anions on Fe dissolution}

Fig. S1 demonstrated that Fe solubility in solutions with $0.1 \mathrm{~mol} \mathrm{~L}^{-1} \mathrm{H}^{+}$(as $\mathrm{HCl}$ ) and $3 \mathrm{~mol}$ $\mathrm{L}^{-1} \mathrm{NH}_{4} \mathrm{Cl}$ (red triangles) is higher than that in sulfuric acid solution at a dust/liquid ratio of $1 \mathrm{~g}$ $\mathrm{L}^{-1}$ (blue squares). This is consistent with higher $H^{+}$activity in $3 \mathrm{~mol} \mathrm{~L}^{-1} \mathrm{NH}_{4} \mathrm{Cl}$ solution (larger than 1 and so the predicted $\mathrm{pH}$ is 0.9 ). However, the measured $\mathrm{Fe}$ solubility in $\mathrm{HCl}$ is lower than that measured at a dust/liquid ratio of $60 \mathrm{mg} \mathrm{L}^{-1}\left(\left[\mathrm{H}^{+}\right]=0.1 \mathrm{~mol} \mathrm{~L}^{-1}\right)$ in sulfuric acid solution only (black circles). Thus the dissolution of Fe minerals is suppressed at higher dust/liquid ratio $\left(1 \mathrm{~g} \mathrm{~L}^{-1}\right)$, likely due to weak complex of $\mathrm{Cl}^{-}$with $\mathrm{Fe}^{3+}$ (Meskhidze et al., 2005; Hsu et al., 2007). This is consistent with previous laboratory measurements (Hamer et al., 2003; Shi et al., 2011).

\section{Comparison of modeled and measured Fe dissolution for illite}

When dissolution rates are normalized to Brunauer, Emmett and Teller (BET) specific surface areas of minerals, the dissolution rates of chlorite are more than an order of magnitude higher than those for smectite and illite (Zysset and Schindler, 1996; Bauer and Berger, 1998; Brandt et al., 2003; Köhler et al., 2003; Amram and Ganor, 2005; Lowson et al., 2005; Golubev et al., 2006; Rozalén et al., 2008). However, the BET surface area does not represent the reactive surface area of nano-sized Fe oxides and phyllosilicate minerals (Brandt et al., 2003; Rozalén et al., 2008; Lanzl et al., 2012). A weak correlation $(\mathrm{R}=0.27)$ between the total dissolved Fe and BET surface area was also found for the Fe dissolution experiment of combustion aerosols (Chen and Grassian, 2013). The similarity in the dissolution rates normalized to mass of the aluminosilicates suggests that similar clay structures dissolve by similar mechanisms (see Fig. 10 in Rozalén et al., 2008). To examine whether our Fe dissolution scheme can reproduce the Fe release rates measured for illite (Shi et al., 2011), a comparison of the Fe solubility for illite at $\mathrm{pH}=2$ under dark conditions due to proton-promoted Fe dissolution is shown in Fig. S2. The comparison exercise reveals that both the calculations using the Fe release rate for mineral dust in this work (red squares) and that for illite in Ito and $\mathrm{Xu}$ (2014) (blue squares) reproduce the Fe solubility change with time on the timescale of aerosol lifetime. In Ito and $\mathrm{Xu}$ (2014), illite dissolution rate at stage III was calculated using potassium $(\mathrm{K})$ release rate between 144 and 840 hours of reaction time (Nagy, 1995). Because of the high initial release rate of $\mathrm{K}$ at $\mathrm{pH}=2$ before reaching a steady state, the Fe dissolution from illite used in Ito and $\mathrm{Xu}$ (2014) is significantly faster than that from structural Fe under steady state conditions (Journet et al., 2008; Bibi et al., 2011). 


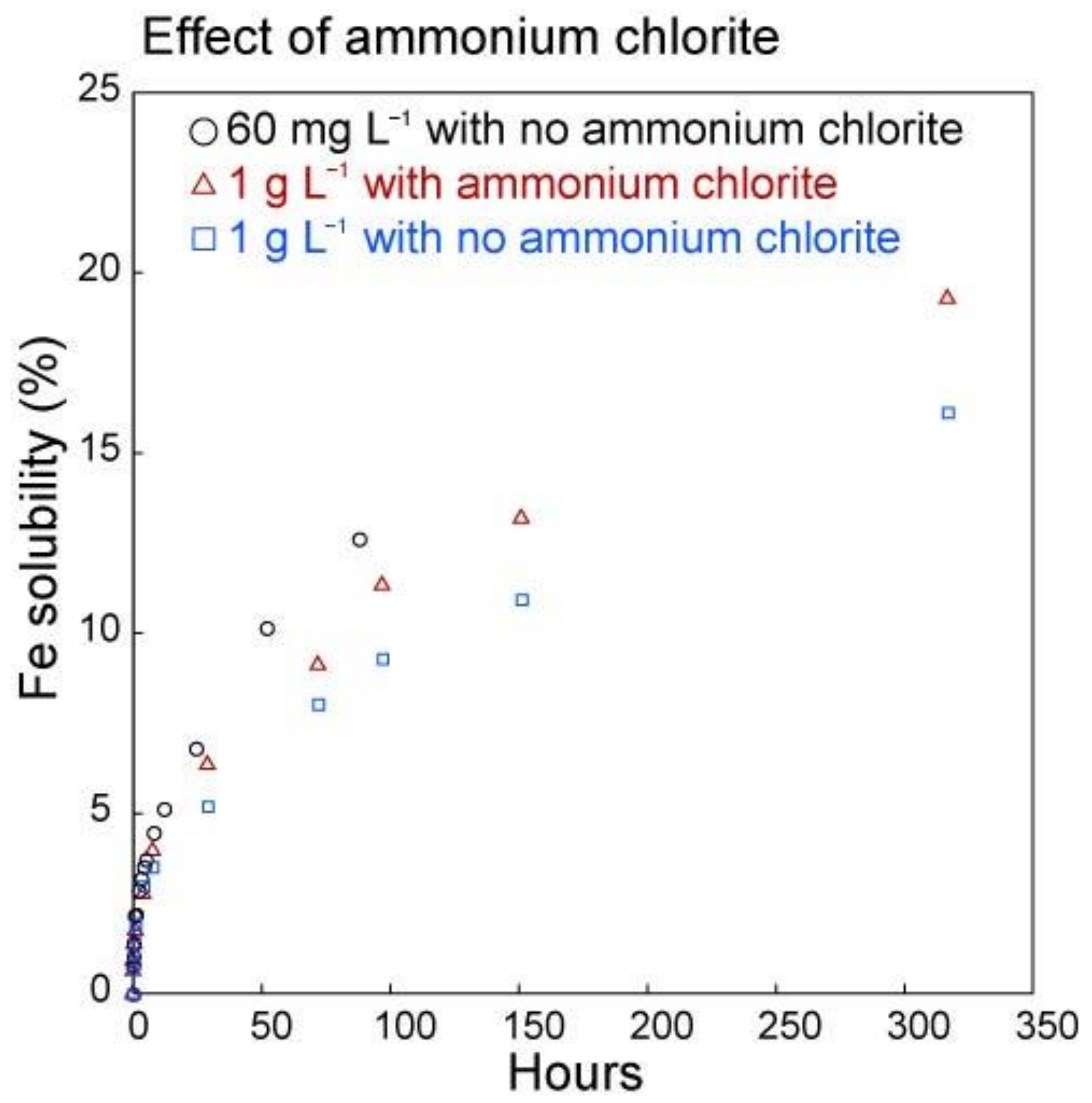

Fig. S1 Comparison of Fe solubility in solution (\%) measured at a dust/liquid ratio of $1 \mathrm{~g} \mathrm{~L}^{-1}$ in $0.05 \mathrm{~mol} \mathrm{~L}^{-1}$ sulfuric acid solution (blue squares, $\mathrm{pH}=1.3, I=0.15 \mathrm{~mol} \mathrm{~L}^{-1}$ ), in $0.1 \mathrm{~mol} \mathrm{~L}^{-1}$ $\mathrm{HCl}$ solution with $3 \mathrm{~mol} \mathrm{~L}^{-1} \mathrm{NH}_{4} \mathrm{Cl}$ (red triangles, $\mathrm{pH}=0.9, I=3.2 \mathrm{~mol} \mathrm{~L}^{-1}$ ), and at a dust/liquid ratio of $60 \mathrm{mg} \mathrm{L}^{-1}$ in $0.05 \mathrm{~mol} \mathrm{~L}^{-1}$ sulfuric acid solution (black circles, $\mathrm{pH}=1$ ) (Shi et al., 2011). 


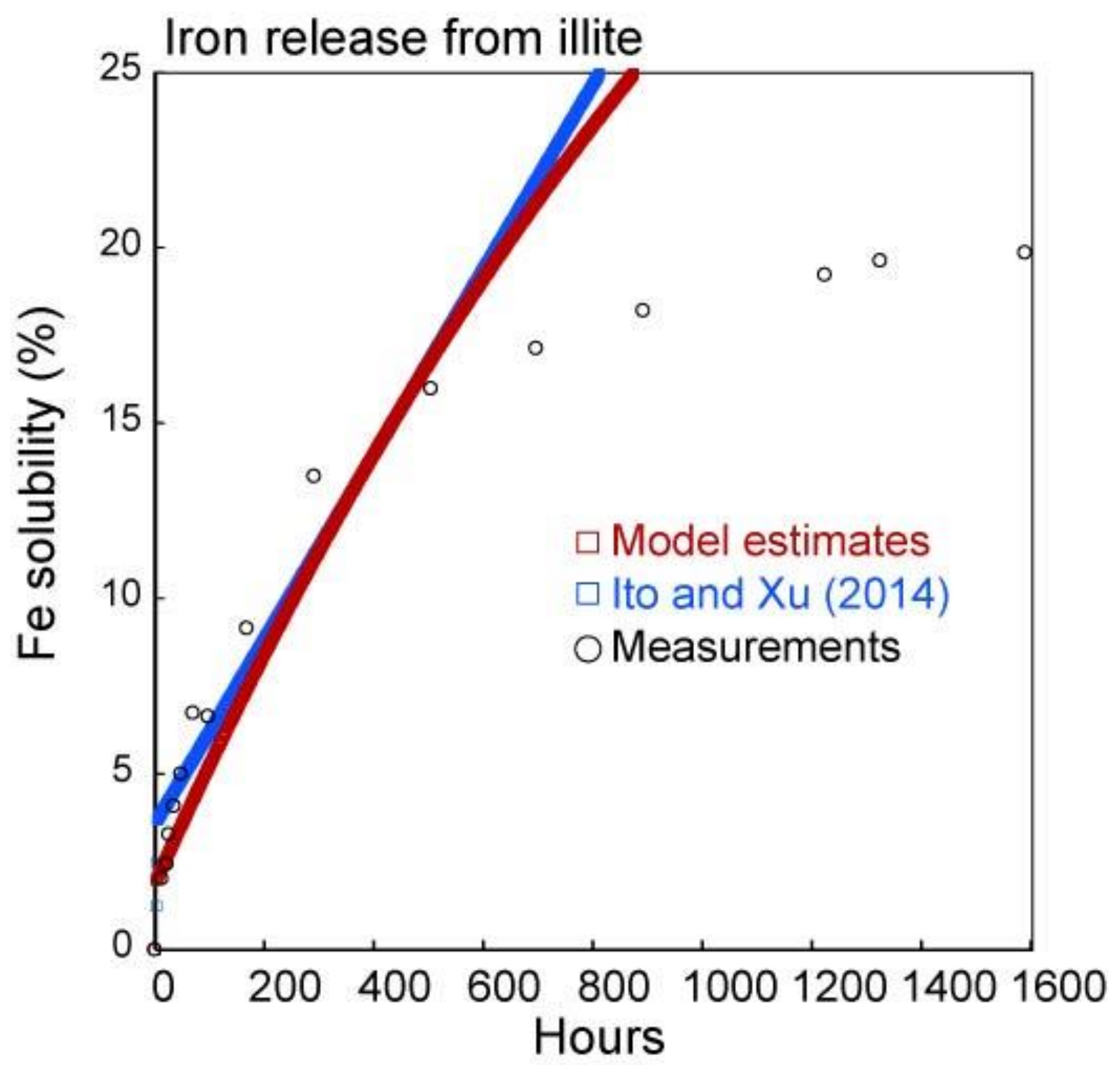

Fig. S2 Comparison of Fe solubility in solution (\%) predicted using equation (1) with the measured $\mathrm{Fe}$ dissolution rates of illite at $\mathrm{pH}=2$. The red squares are calculated using equation (1) from rate constants for Fe-containing mineral dust used in this study at each hour. The blue squares are calculated using equation (1) from rate constants for illite used in Ito and Xu (2014). The black circles are the measured data for illite (Shi et al., 2011). The fraction of total dissolved Fe present as $\mathrm{Fe}(\mathrm{III})$ is prescribed at $\mathrm{pH}=2(0.2)$ in this calculation to emulate the experimental conditions, while the photochemical redox cycling between $\mathrm{Fe}(\mathrm{III})$ and $\mathrm{Fe}(\mathrm{II})$ in solution is explicitly simulated in our global model (Lin et al., 2014). The large fraction of Fe(II) in solution under the dark conditions is likely associated with the preferential $\mathrm{Fe}(\mathrm{II})$ release (Bibi et al., 2011). 
(a) Dust aerosol $\mathrm{pH}$ in bin 1

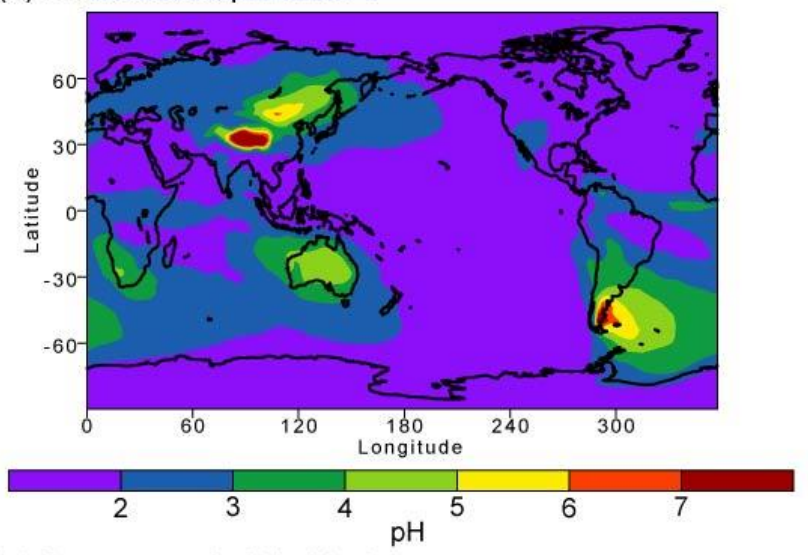

(c) Dust aerosol $\mathrm{pH}$ in bin 3

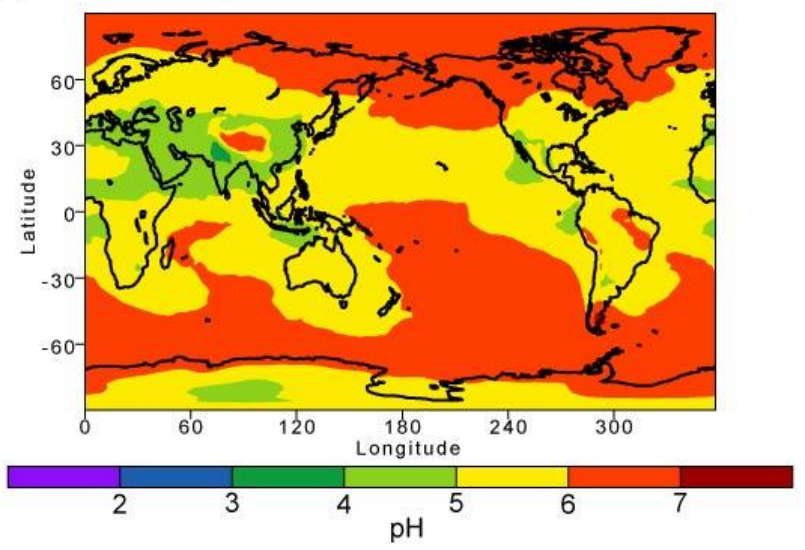

(b) Dust aerosol $\mathrm{pH}$ bin 2

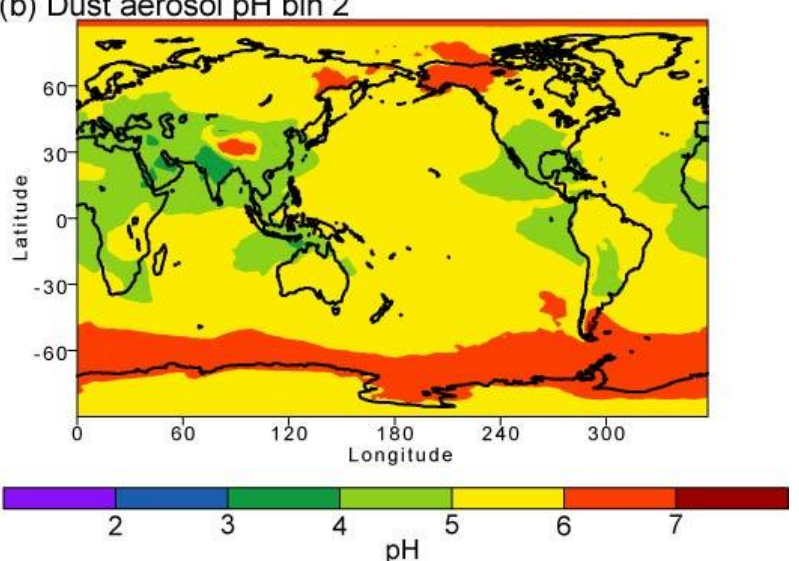

(d) Dust aerosol pH bin4

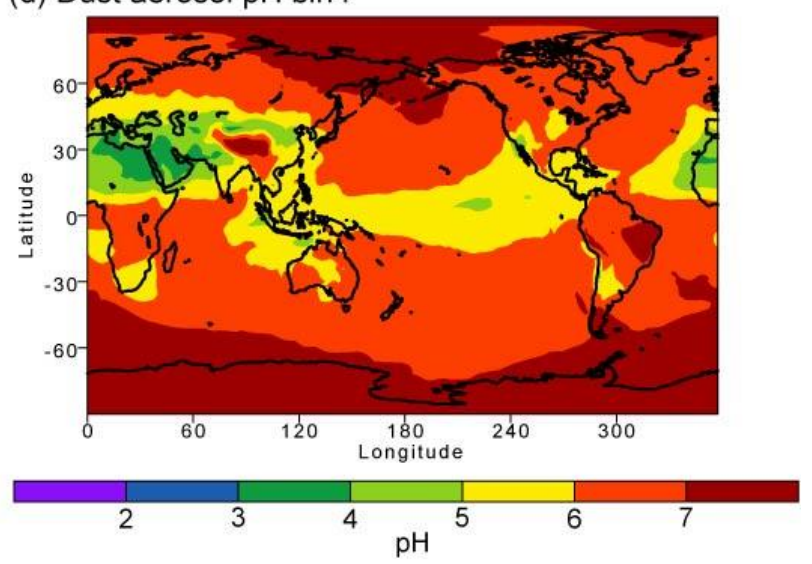

Fig. S3 Spatial distribution of vertically and annually averaged dust $\mathrm{pH}$ for (a) bin 1 (radius: $<0.63 \mu \mathrm{m}$ ), (b) bin 2 (radius: $0.63-1.25 \mu \mathrm{m}$ ), (c) bin 3 (radius: $1.25-2.5 \mu \mathrm{m}$ ), and (d) bin 4 (radius: $2.5-10 \mu \mathrm{m}$ ) for the present day. 


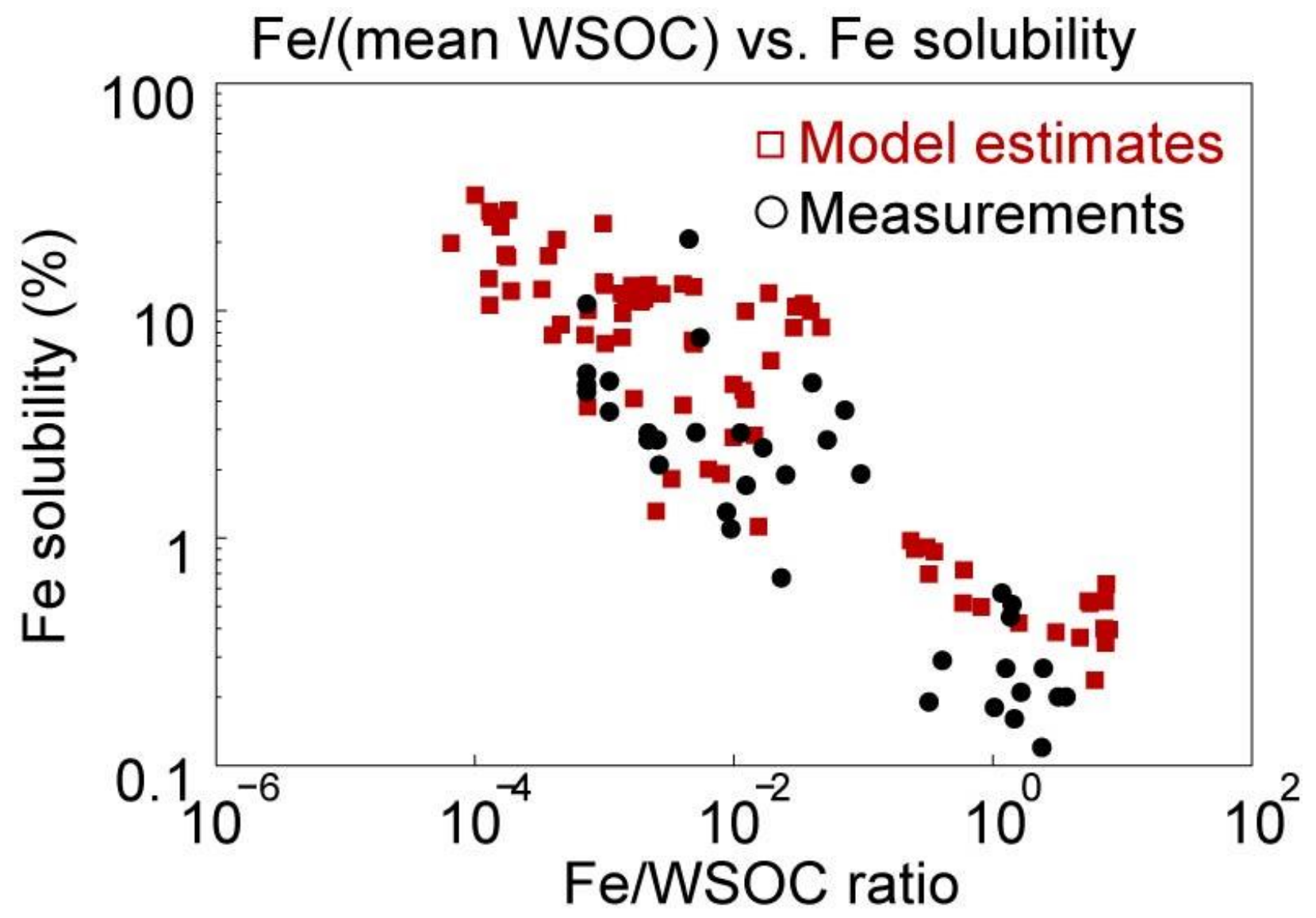

Fig. S4 The Fe/WSOC molar ratio versus Fe solubility for model estimates (red squares) and measurements (black circles) over the cruise tracks. The measurements are obtained from Wozniak et al., (2013, 2015). The number of modeled data points (84) is larger than the measurements (37), because each daily average is calculated for each sampling date at each center of cruise location. A constant WSOC concentration at $330\left(\mathrm{ng} \mathrm{m}^{-3}\right)$ is used for both the model estimates and measurements in this figure for a comparison with Fig. 5b. 
(a) Proton/total soluble Fe deposition from base case

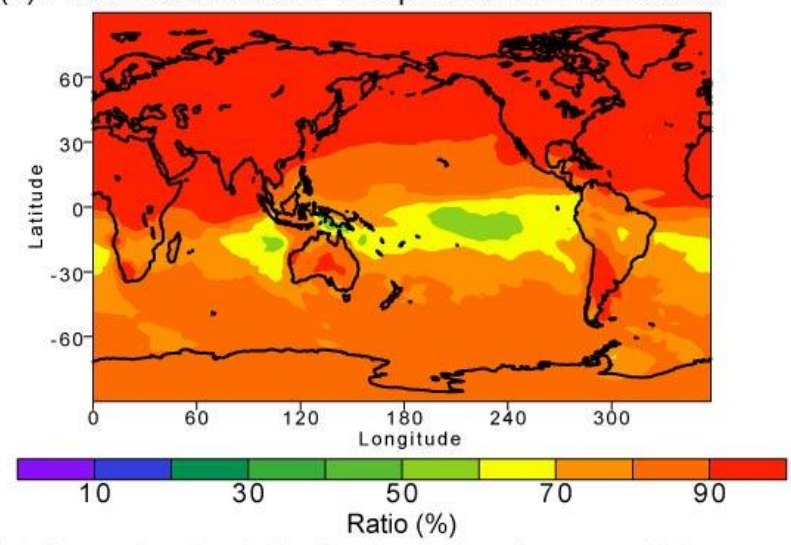

(c) Proton/total soluble Fe deposition from sensitivity case

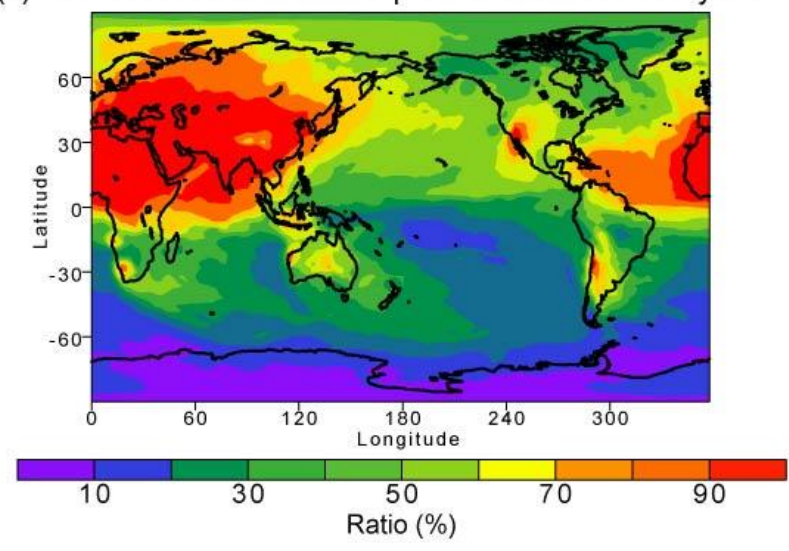

(b) Oxalate/total soluble Fe deposition from base case

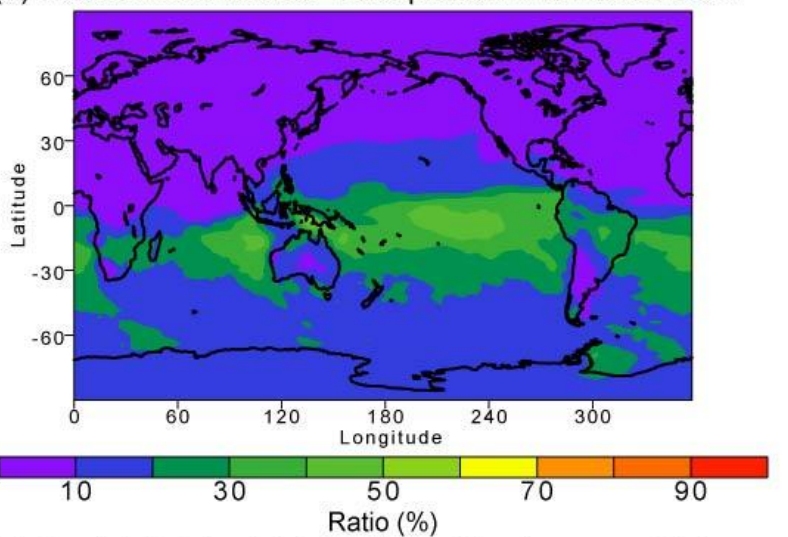

(d) Oxalate/total soluble Fe deposition from sensitivity case

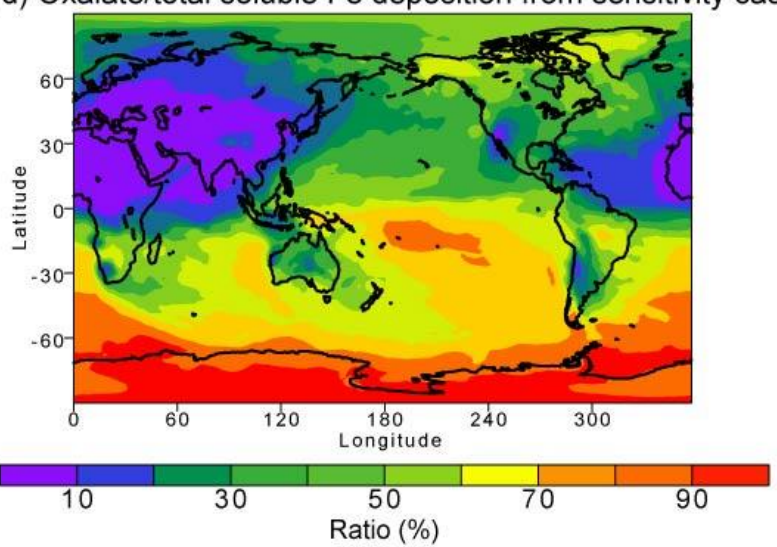

Fig. S5 Contribution of proton-promoted scheme and oxalate-promoted scheme to the total soluble Fe deposition calculated in the base and sensitivity simulations for dust aerosols. (a) Ratio (\%) of the soluble Fe deposition from proton-promoted scheme $(i=1)$ to the total soluble Fe deposition in the base simulations, (b) ratio (\%) of the soluble Fe deposition from oxalatepromoted scheme $(i=2)$ to the total soluble Fe deposition in the base simulations, (c) ratio (\%) of the soluble $\mathrm{Fe}$ deposition from proton-promoted scheme $(i=1)$ to the total soluble $\mathrm{Fe}$ deposition in the sensitivity simulations, and (d) ratio (\%) of the soluble Fe deposition from oxalate-promoted scheme ( $i=2$ and 3 ) to the total soluble Fe deposition in the sensitivity simulations. The formation of the amorphous $\mathrm{Fe}(\mathrm{OH})_{3}(\mathrm{~s})$ suppresses the oxalate-promoted dissolution from mineral aerosols in the base simulations, while no such effect was considered for quasi-light-induced reductive dissolution in the sensitivity simulation (i.e., $f_{3}=1$ ). 
(a) Proton/total soluble Fe deposition from additional case

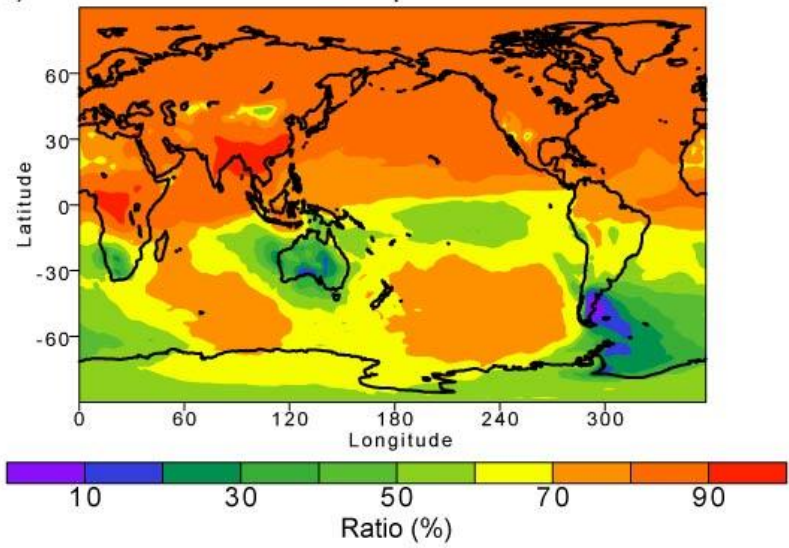

(b) Oxalate/total soluble Fe deposition from additional case

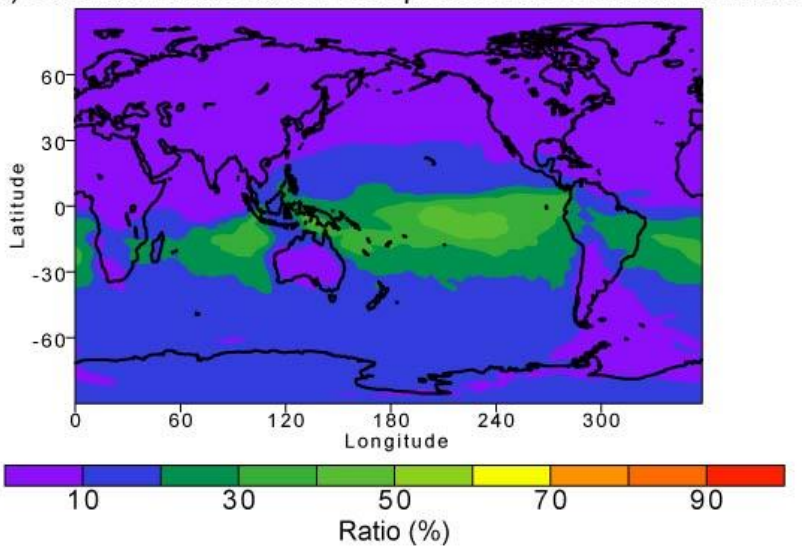

(c) Primary/total soluble Fe deposition from additional case

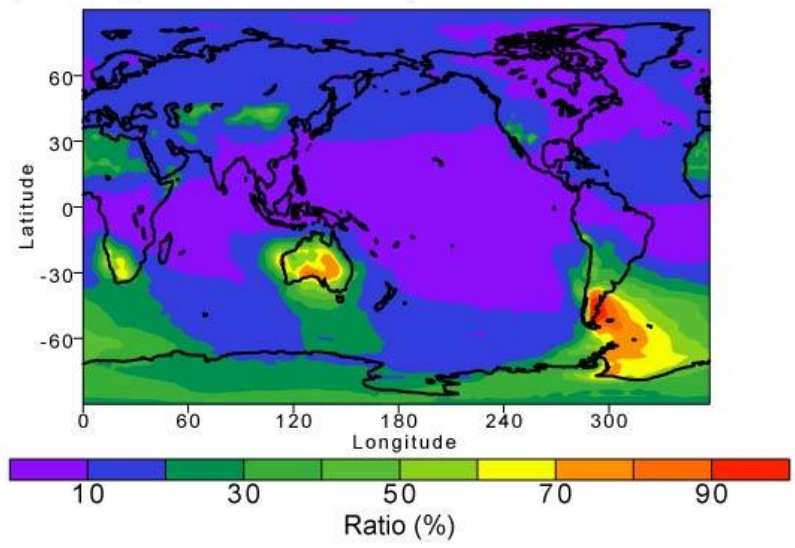

Fig. S6 Contribution of proton-promoted scheme, oxalate-promoted scheme, and soluble Fe at emission to the total soluble Fe deposition calculated in additional sensitivity simulations for dust aerosols. To demonstrate the effect of different assumption on the initial period of enhanced Fe release for a comparison with Fig. S5, we use $0.1 \%$ for the initial Fe solubility of mineral dust in additional sensitivity simulations (Hand et al., 2004; Ito and $\mathrm{Xu}, 2014$ ). (a) ratio (\%) of the soluble Fe deposition from proton-promoted scheme $(i=1)$ to the total soluble Fe deposition in additional sensitivity simulations, (b) ratio (\%) of the soluble Fe deposition from oxalatepromoted scheme $(i=2$ and 3$)$ to the total soluble Fe deposition in additional sensitivity simulations, and (c) ratio (\%) of the soluble Fe deposition from the primary soluble Fe to the total soluble Fe deposition in additional sensitivity simulations. 


\section{Anthropogenic soluble Fe with $0.1 \%$ initial Fe solubility}

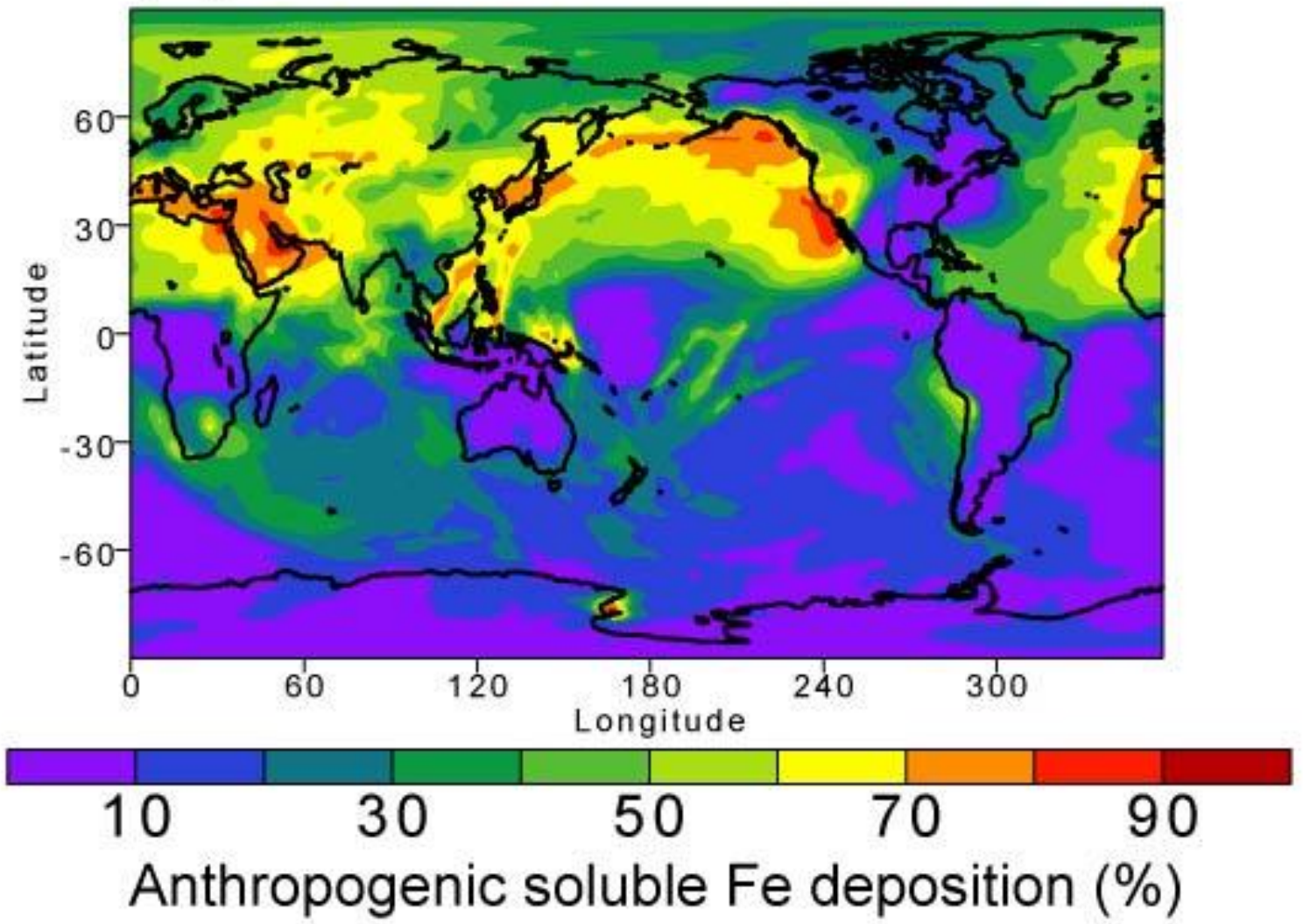

Fig. S7 Ratio of anthropogenic to total soluble Fe deposition in the present day from additional sensitivity simulations. To demonstrate the effect of different assumption on the initial period of enhanced Fe release for a comparison with $0 \%$ for the initial Fe solubility of mineral dust in Fig. 7f, we assumed an initial Fe solubility of mineral dust of $0.1 \%$ in an additional sensitivity simulation (Hand et al., 2004; Ito and $\mathrm{Xu}, 2014$ ). 


\section{References}

Amram, K. and Ganor, J.: The combined effect of $\mathrm{pH}$ and temperature on smectite dissolution rate under acidic conditions, Geochim. Cosmochim. Acta, 69, 2535-2546, doi:10.1016/j.gca.2004.10.001, 2005.

Bauer, A. and Berger, G.: Kaolinite and smectite dissolution rate in high molar KOH solutions at $35^{\circ} \mathrm{C}$ and $80^{\circ} \mathrm{C}$, Appl. Geochem. 13, 905-916, 1998.

Bibi, I., Singh, B., and Silvester, E.: Dissolution of illite in saline-acidic solutions at $25^{\circ}$ C, Geochim. Cosmochim. Acta, 75, 3237-3249, doi:10.1016/j.gca.2011.03.022, 2011.

Brandt, F., Bosbach, D., Krawczyk-Bärsch, E., Arnold, T., and Bernhard, G.: Chlorite dissolution in the acid pH-range: A combined microscopic and macroscopic approach, Geochim. Cosmochim. Acta, 67, 1451-1461, doi:10.1016/S0016-7037(02)01293-0, 2003.

Cama, J. and Ganor, J.: The effects of organic acids on the dissolution of silicate minerals: A case study of oxalate catalysis of kaolinite dissolution, Geochim. Cosmochim. Acta, 70(9), 2191-2209, doi:10.1016/j.gca.2006.01.028, 2006.

Chen, H. and Grassian, V. H.: Iron dissolution of dust source materials during simulated acidic processing: The effect of sulfuric, acetic, and oxalic acids, Environ. Sci. Technol., 47, 10312-10321, doi:10.1021/es401285s, 2013.

Cornell, R. M. and Schwertmann, U.: The iron oxides: Structure, properties, reactions, occurrence and uses, Wiley-VCH publishers, New York, 2003.

Golubev, S. V., Bauer, A., and Pokrovsky, O. S.: Effect of $\mathrm{pH}$ and organic ligands on the kinetics of smectite dissolution at $25^{\circ} \mathrm{C}$, Geochim. Cosmochim. Acta, 70(17), 4436-4451, doi:10.1016/j.gca.2006.06.1557, 2006.

Hamer, M., Graham, R., Amrhein, C., and Bozhilov, K.: Dissolution of ripidolite (Mg, Fechlorite) in organic and inorganic acid solutions, Soil Sci. Soc. Am. J., 67 (2), 654-661, 2003.

Hand, J. L., Mahowald, N. M., Chen, Y., Siefert, R. L., Luo, C., Subramaniam, A., and Fung, I.: Estimates of atmosphericprocessed soluble iron from observations and a global mineral aerosol model: Biogeochemical implications, J. Geophys. Res., 109, D17205, doi:10.1029/2004JD004574, 2004.

Hsu, C.-L., Wang, S.-L., and Tzou, Y.-M.: Photocatalytic reduction of Cr (VI) in the presence of $\mathrm{NO}_{3}{ }^{-}$and $\mathrm{Cl}^{-}$electrolytes as influenced by Fe (III), Environ. Sci. Technol., 41(22), 79077914, doi:10.1021/es0718164, 2007.

Ito, A.: Atmospheric processing of combustion aerosols as a source of bioavailable iron, Environ. Sci. Technol. Lett., 2 (3), 70-75, doi: 10.1021/acs.estlett.5b00007, 2015.

Ito, A. and $\mathrm{Xu}$, L.: Response of acid mobilization of iron-containing mineral dust to improvement of air quality projected in the future, Atmos. Chem. Phys., 14, 3441-3459, 
doi:10.5194/acp-14-3441-2014, 2014.

Johnson, M. S., and Meskhidze, N.: Atmospheric dissolved iron deposition to the global oceans: effects of oxalate-promoted Fe dissolution, photochemical redox cycling, and dust mineralogy, Geosci. Model Dev., 6, 1137-1155, doi:10.5194/gmd-6-1137-2013, 2013.

Journet, E., Desboeufs, K. V., Caquineau, S., and Colin, J.-L.: Mineralogy as a critical factor of dust iron solubility, Geophys. Res. Lett., 35, L07805, doi:10.1029/2007GL031589, 2008.

Köhler, S. J., Dufaud, F., and Oelkers, E. H.: An experimental study of illite dissolution kinetics as a function of $\mathrm{pH}$ from 1.4 to 12.4 and temperature from 5 to $50^{\circ} \mathrm{C}$, Geochim. Cosmochim. Acta, 67(19), 3583-3594, doi:10.1016/S0016-7037(03)00163-7, 2003.

Lowson, R. T., Comarmond, M. C. J., Rajaratnam, G., and Brown, P. L.: The kinetics of the dissolution of chlorite as a function of $\mathrm{pH}$ and at $25^{\circ} \mathrm{C}$, Geochim. Cosmochim. Acta, 69(7), 1687-1699, doi:10.1016/j.gca.2004.09.028, 2005.

Meskhidze, N., Chameides, W. L., and Nenes, A.: Dust and pollution: A recipe for enhanced ocean fertilization?, J. Geophys. Res., 110, D03301, doi:10.1029/2004JD005082, 2005.

Myriokefalitakis, S., Daskalakis, N., Mihalopoulos, N., Baker, A. R., Nenes, A., and Kanakidou, M.: Changes in dissolved iron deposition to the oceans driven by human activity: a 3-D global modelling study, Biogeosciences, 12, 3973-3992, doi:10.5194/bg-12-3973-2015, 2015.

Lanzl, C. A., Baltrusaitis, J., and Cwienty, D. M.: Dissolution of hematite nanoparticle aggregates: Influence of primary particle size, dissolution mechamism, and solution $\mathrm{pH}$, Langmuir, 28, 15797-15808, doi:10.1021/la3022497, 2012.

Lin, G., Sillman, S., Penner, J. E., and Ito, A.: Global modeling of SOA: the use of different mechanisms for aqueous-phase formation, Atmos. Chem. Phys., 14, 5451-5475, doi:10.5194/acp-14-5451-2014, 2014.

Luo, C. and Gao, Y.: Aeolian iron mobilisation by dust-acid interactions and their implications for soluble iron deposition to the ocean: a test involving potential anthropogenic organic acidic species, Environ. Chem., 7, 153-161, doi:10.1071/EN09116, 2010.

Nagy, K. L.: Dissolution and precipitation kinetics of sheet silicates, Rev. Min., 31, 173-225, 1995.

Paris, R., Desboeufs, K. V., and Journet, E.: Variability of dust iron solubility in atmospheric waters: Investigation of the role of oxalate organic complexation, Atmos. Environ., 45, 65106517, doi:10.1016/j.atmosenv.2011.08.068, 2011.

Rozalén, M. L., Huertas, F. J., Brady, P. V., Cama, J., García-Palma, S., and Linares, J.: Experimental study of the effect of $\mathrm{pH}$ on the kinetics of montmorillonite dissolution at $25^{\circ} \mathrm{C}$, Geochim. Cosmochim. Acta, 72(17), 4224-4253, doi:10.1016/j.gca.2008.05.065, 2008.

Shi, Z., Bonneville, S., Krom, M., Carslaw K., Jickells, T., Baker, A., and Benning, L.: Iron 
dissolution kinetics of mineral dust at low $\mathrm{pH}$ during simulated atmospheric processing, Atmos. Chem. Phys., 11, 995-1007, doi:10.5194/acp-11-995-2011, 2011.

Wozniak, A. S., Shelley, R. U., Sleighter, R. L., Abdulla, H. A. N., Morton, P. L., Landing, W. M., and Hatcher, P. G.: Relationships among aerosol water soluble organic matter, iron and aluminum in European, North African, and Marine air masses from the 2010 US GEOTRACES cruise, Mar. Chem., 153, 24-33, doi:10.1016/j.marchem.2013.04.011, 2013.

Wozniak, A. S., Shelley, R. U., McElhenie, S. D., Landing, W. M., and Hatcher, P. G.: Aerosol water soluble organic matter characteristics over the North Atlantic Ocean: Implications for iron-binding ligands and iron solubility, Mar. Chem., 173, 162-172, doi:10.1016/j.marchem.2014.11.002, 2015.

$\mathrm{Xu}, \mathrm{N}$. and Gao, Y.: Characterization of hematite dissolution affected by oxalate coating, kinetics and pH, Appl. Geochem., 23, 783-793, doi:10.1016/j.apgeochem.2007.12.026, 2008.

Yoon, T. H., Johnson, S. B., Musgrave, C. B., and Brown, G. E.: Adsorption of organic matter at mineral/water interfaces: I. ATR-FTIR spectroscopic and quantum chemical study of oxalate adsorbed at boehmite/water and corundum/water interfaces, Geochim. Cosmochim. Acta, 68(22), 4505-4518, doi:10.1016/j.gca.2004.04.025, 2004.

Yu, J. Z., Huang, X.-F., Xu, J., and Hu, M.: When aerosol sulfate goes up, so does oxalate: Implication for the formation mechanisms of oxalate, Environ. Sci. Technol., 39, 128-133, doi:10.1021/es049559f, 2005.

Zysset, M. and Schindler, P. W.: The proton promoted dissolution kinetics of K-montmorillonite, Geochim. Cosmochim. Acta, 60(6), 921-931, 1996. 